\title{
Trichotillomania Incognito: Two Case Reports and Literature Review
}

\author{
Mariana Rita de Novaes Fernandes ${ }^{a}$ Daniel Fernandes Melo ${ }^{a}$ \\ Colombina Vincenzi ${ }^{b}$ Caren dos Santos Lima ${ }^{c, d}$ Antonella Tosti ${ }^{\mathrm{e}}$
}

aDermatology Department, University of State of Rio de Janeiro (UERJ), Rio de Janeiro, Brazil; bermatology Department, Private Hospital Nigrisoli, Bologna, Italy; ' Dermatology Department, University of State of Pará (UEPA), Belém, Brazil; dDermatology Department, University Center of Pará (CESUPA), Belém, Brazil; 'Dr. Phillip Frost Department of Dermatology and Cutaneous Surgery University of Miami School of Medicine, Miami, FL, USA

\section{Established Facts}

- Trichotillomania is defined as an obsessive-compulsive or related disorder in which person recurrently pulls out hair from any region of their body resulting in hair loss.

- Trichotillomania is a distressful condition that affects mainly female preadolescents. This disease usually presents with a bizarre pattern nonscarring patchy alopecia.

\section{Novel Insights}

- We report 2 cases of pediatric trichotillomania without patches, a subject not previously described in the medical literature.

- We reinforce the relevance of trichoscopy in all hair disorder evaluation, which allowed in these cases the early recognition of trichotillomania even though they are subclinical cases.

\section{Keywords}

Pediatric trichotillomania · Trichotillomania · Hairpulling •

Trichoscopy

\section{Abstract}

Trichotillomania is a compulsive disorder characterized by repetitive hairpulling. It is an important cause of patchy alopecia, especially in children between 9 and 13 years of age. The aim of this paper is to report 2 pediatric cases presenting with trichotillomania without patches. This condition may be extremely distressful, impacting psychosocial develop- ment of children. In these case reports, we reinforce the relevance of trichoscopy in hair disorder evaluation, which allowed early recognition to better advise and conduct these unique pediatric cases.

(c) 2020 S. Karger AG, Basel

\section{Introduction}

Trichotillomania is a compulsive disorder characterized by repetitive hairpulling that predominantly affects parietal and occipital regions of the scalp. Trichotilloma- 


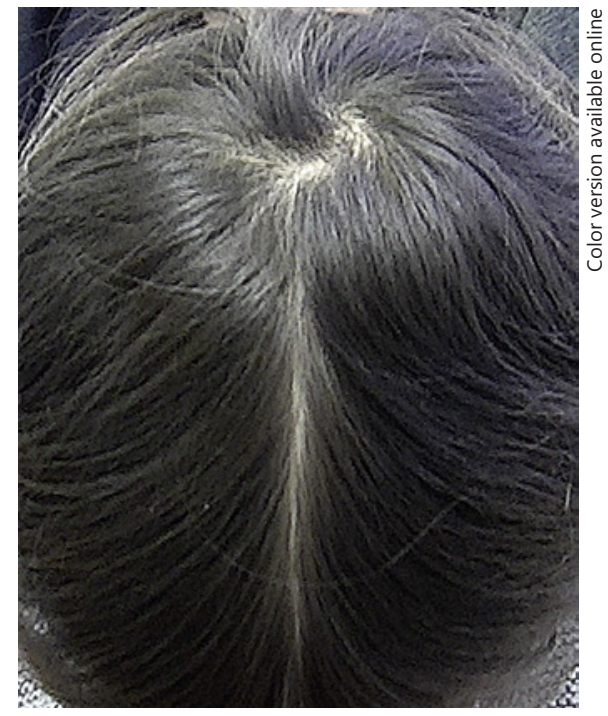

Fig. 1. A healthy 4-year-old girl was referred to our service because her mother complained about slow hair growth. Assessment of the scalp revealed low hair density in the occipital and parietal region without any patch.

nia is an important cause of patchy alopecia, especially in female pre-teenagers [1-3]. Trichotillomania is often underdiagnosed and little is known about this condition in childhood [4]. The diagnosis is frequently difficult and may be challenging to differentiate trichotillomania from other causes of nonscarring alopecia. Trichoscopy is a noninvasive tool that has shown great value in confirming trichotillomania in doubtful cases $[5,6]$. The aim of this paper was to report 2 pediatric cases presenting with trichotillomania without patchy alopecia.

\section{Case Presentation}

\section{Case 1}

A healthy 4-year-old girl was referred for our evaluation because her mother complained about slow hair growth. Assessment of scalp revealed low hair density in occipital and parietal region, without any patch (shown in Fig. 1). Trichoscopy showed broken hairs, hair powder, and flame hair (shown in Fig. 2). a pull test was negative; the scalp surface and hair shaft had a normal appearance. The patient did not practice trichophagia or nail biting. When questioned, her mother explained that the child used to roll the hair around her fingers before falling asleep.

\section{Case 2}

A healthy 14-year-old girl came to our evaluation complaining of hair loss in the past 3 months due to increased anxiety. On scalp examination, low hair density was observed in occipital region, without any patch of alopecia (shown in Fig. 3). Trichoscopy revealed irregular black dots, broken hairs, and hair powder in the

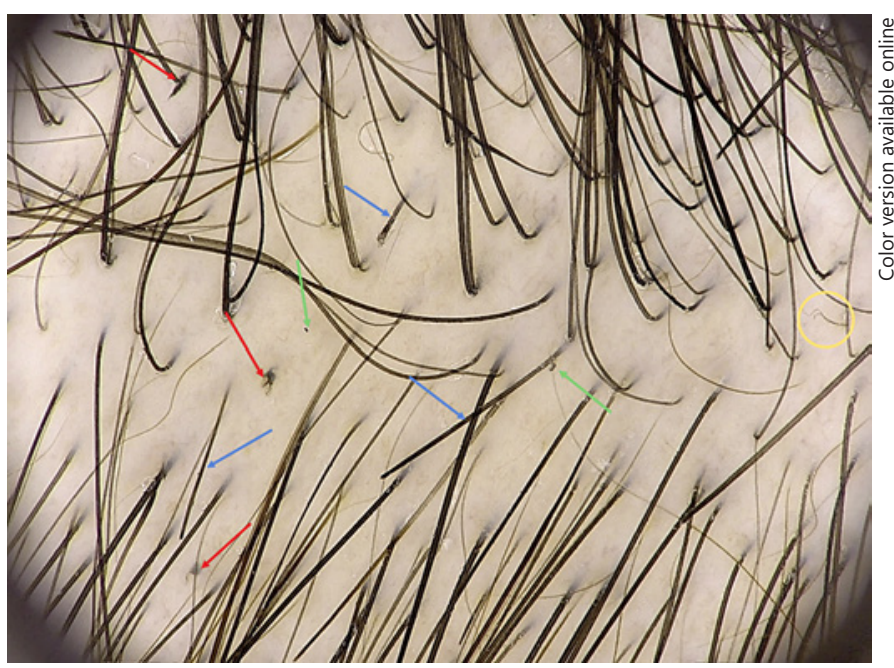

Fig. 2. Trichoscopy image showing signs of trichotillomania such as broken hairs (blue arrows), flame hairs (red arrows), hair powder (green arrows), and trichoptilosis (yellow circle). Fotofinder Dermoscope ${ }^{\circledR}$, Germany, at 20 -fold magnification.

affected area (shown in Fig. 4). A hair pull test was negative. The scalp surface and hair shafts did not show dermatological abnormalities. The patient did not practice trichophagia or nail biting. When questioned, she confessed that she used to pull her hair out when anxious despite omitting it from her mother.

\section{Discussion/Conclusion}

Trichotillomania is defined by the Diagnostic and Statistical Manual of Mental Disorders as an obsessive-compulsive or related disorder in which person recurrently pulls out hair from any region of their body resulting in hair loss $[5,7]$. Trichotillomania is a highly comorbid disorder, with a lifetime prevalence of concomitant psychiatric disorder as high as $80 \%$. The most common associated disorders are anxiety, major depression, substance abuse, eating disorders, post-traumatic stress disorder, personality disorders, and body dysmorphic disorder. It has been reported to overlap with skin picking and nail biting [8].

Trichotillomania most often affects female children between 9 and 13 years of age (70-93\% of cases) who generally deny the habit [1]. This condition normally presents with a bizarre pattern, nonscarring patchy alopecia [4].

Trichotillomania is usually diagnosed based on clinical features and, in doubtful cases, trichoscopy and/or a 


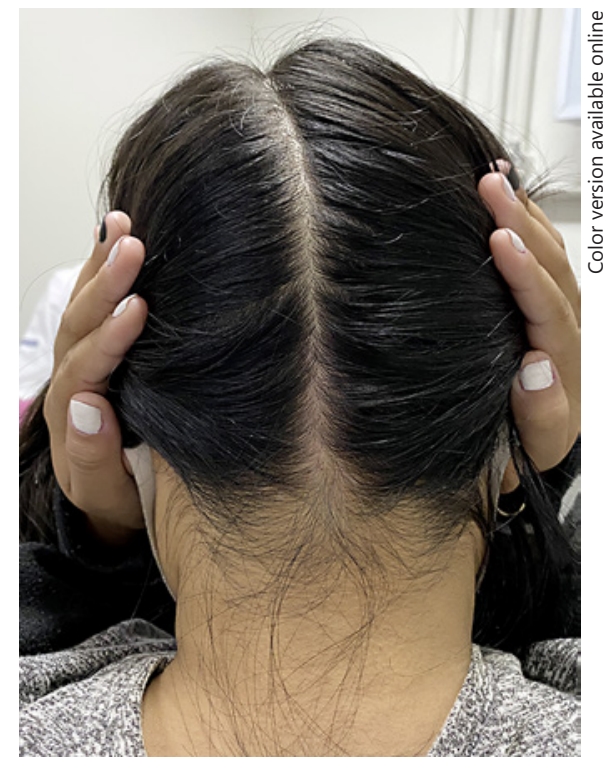

Fig. 3. A healthy 14-year-old girl complaining about hair rarefaction. Scalp examination revealed low hair density in the occipital region without any patch.

scalp biopsy [1]. The first presented case differs from classic trichotillomania as the child was noticeably young and did not have any patch of alopecia but the complaint was instead slow hair growth. Trichoscopy examination showed broken hairs, hair powder, and flame hair. In the second case, the patient complained about hair rarefaction; however, she did not present with patches of alopecia on the scalp. Trichoscopy revealed irregular black dots, broken hairs in different lengths, and hair powder. Others trichotillomania trichoscopic findings are trichoptilosis, hook hair, coiled hair, tulip hair, and V-sign hair $[1,9]$.

Diagnosing scalp trichotillomania in pediatric patients is often tough as other disorders have similar clinical presentation, mainly alopecia areata and tinea capitis $[1,10]$. Two types of hairpulling have been described for trichotillomania: automatic and focused $[3,5]$. Automatic occurs outside of one's own awareness, while focused pulling happens in awareness and in response to negative emotional states, such as stress, sadness, anger, or anxiety $[3,5,8]$. Younger children more often fall in the automatic category; therefore, they do not recall actual pulling but may admit to "play with hair." On the other hand, older children tend to manifest focused pulling in response to stressful events $[5,8]$.

In the first case presented, the child played with her hair, leading to traction and pullout without intention of

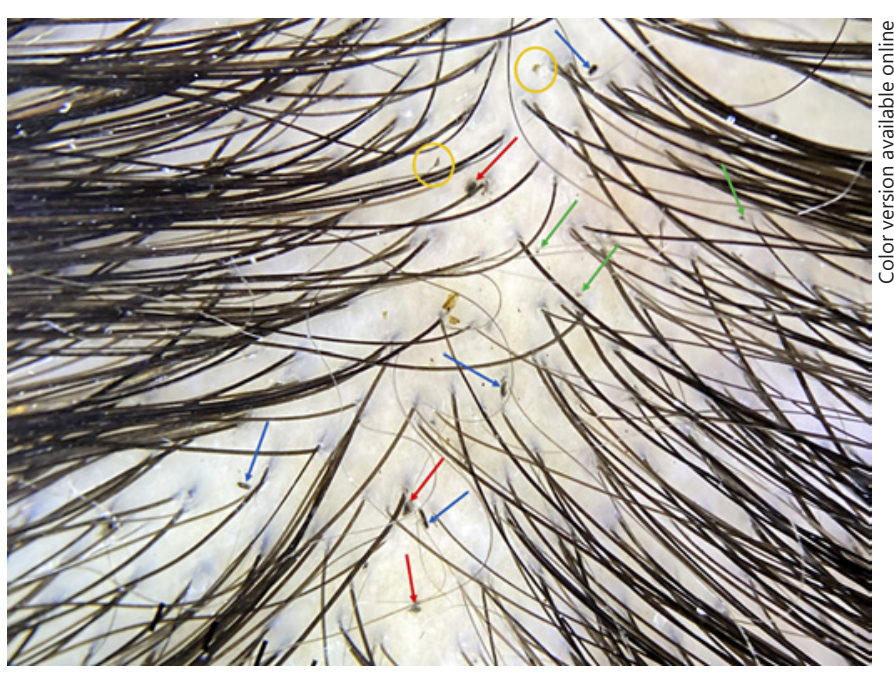

Fig. 4. Trichoscopy image showing signs of trichotillomania such as broken hairs (blue arrows), hair powder (green arrows), flame hairs (yellow circles), and irregular black dots (red arrows). 3Gen DermLite $^{\circledR}$ DL4 at 10 -fold magnification.

pulling. In the second case, even without intention the patient pulled her hair in order to distract herself and relieve anxiety. Trichotillomania may occur in private, leading parents to believe the hair is falling out [4] as observed in both cases. Interestingly, only half of parents notice their child's hairpulling [2].

Trichotillomania may be extremely distressful, impacting psychosocial development of children. To the best of our knowledge, this is the first article reporting cases of trichotillomania without patches. The absence of patches, especially in 2 children with no specific complaint, made this diagnosis even more challenging. We reinforce the relevance of trichoscopy in all hair disorders evaluation, which allowed early recognition to better advise and conduct these unique pediatric cases.

\section{Statement of Ethics}

The study complies with the internationally accepted standards for research practice and reporting. The parents of the subjects have given their written informed consent to publish photos and details of the case.

\section{Conflict of Interest Statement}

The authors have no conflicts of interest to declare. 


\section{Funding Sources}

This research did not receive any specific grant from funding agencies in the public, commercial, or not-for-profit sectors.

\section{Author Contributions}

A.T. conceived the study. M.R.F., D.F.M., and C.S.L. wrote the manuscript and collected data. A.T. and C.V. revised discussed the results and reviewed the final manuscript.

\section{References}

1 Martín JM, Montesinos E, Cordero P, Gonzalez V, Ramon D. Trichoscopy features of trichotillomania. Pediatr Dermatol. 2019; 36(2):265-7.

2 Chandran NS, Novak J, Iorizzo M, Grimalt R, Oranje AP. Trichotillomania in children. Skin Appendage Disord. 2015;1(1):18-24.

3 Henkel ED, Jaquez SD, Diaz LZ. Pediatric trichotillomania: review of management. Pediatr Dermatol. 2019;36(6):803-7.

4 Ankad BS, Naidu MV, Beergouder SL, Sujana L. Trichoscopy in trichotillomania: a useful diagnostic tool. Int J Trichology. 2014;6(4): $160-3$.
5 Panza KE, Pittenger C, Bloch MH. Age and gender correlates of pulling in pediatric trichotillomania. J Am Acad Child Adolesc Psychiatry. 2013;52(3):241-9.

6 Abraham LS, Torres FN, Azulay-Abulafia L. Dermoscopic clues to distinguish trichotillomania from patchy alopecia areata. An Bras Dermatol. 2010;85(5):723-6.

7 Radmanesh M, Shafiei S, Naderi AH. Isolated eyebrow and eyelash trichotillomania mimicking alopecia areata. Int J Dermatol. 2006 May;45(5):557-60.
8 França K, Kumar A, Castillo D, Jafferany M, Hyczy da Costa Neto M, Damevska K, et al. Trichotillomania (hair pulling disorder): clinical characteristics, psychosocial aspects, treatment approaches, and ethical considerations. Dermatol Ther. 2019 Jul;32(4):e12622.

9 Rakowska A, Slowinska M, Olszewska M, Rudnicka L. New trichoscopy findings in trichotillomania: flame hairs, V-sign, hook hairs, hair powder, tulip hairs. Acta Derm Venereol. 2014;94:303-6.

10 Hon KL, Leung AK, Ng PC. Unusual loss of body hair in childhood: trichotillomania or alopecia. Adv Ther. 2008 Apr;25(4):380-7. 